\title{
BEEBOARD: FROM WIIMOTE TO INTERACTIVE WHITEBOARD APPLICATION FOR CLASSROOM
}

\author{
Budi Yulianto and Lusiana Citra Dewi \\ Bina Nusantara University, J1. K.H. Syahdan No.9, Jakarta 11480, Indonesia
}

Received 2013-12-22; Revised 2014-04-20; Accepted 2014-07-01

\begin{abstract}
Teaching and learning process is the main factor in education. The use of whiteboard and marker while teaching is an essential media for delivering knowledge from a lecturer to students. In another side, it can cost in daily operation such as making marker dried because of capped-off, easily smudged and some whiteboard (for projector screen) is difficult to be clean if written. The objective is to design and develop an interactive whiteboard application based on multimedia concept to support effective and interactive learning process in classroom. The system is connected to a WiiMote device via Bluetooth and a projector. The methodology is literature study, observation and system design using Unified Modeling Language (UML) approach. An application that can capture image, record sound and video while teaching process. The system is tested and focused on main teaching activities such as writing (drawing), erasing, capturing and recording. All these functionalities can run very well, but need several improvement for next version.
\end{abstract}

Keywords: Interactive Whiteboard, WiiMote, InfraRed LED Marker, Teaching and Learning, Classroom, Multimedia, UML

\section{INTRODUCTION}

To support teaching activities between lecturers and students, many innovations and technologies are used to modify the classroom facilities (Yulianto et al., 2011). This is including the blackboard. People use blackboard for the first time in 1801 and chalk is used to write on the blackboard. Blackboard is gradually giving way to more interaction between lecturers and students (Eskicioglu and Kopec, 2003). Blackboard has some drawbacks, such as dust and uncomfortable sound produced from chalk. In the year 1960, emerged new innovation known as whiteboard. This whiteboard can cover few of blackboard's drawbacks. It is made from melamine and used with markers to write (Fig. 1). But still, there are a few drawbacks in using the whiteboard, such as higher price for markers than chalks, quick-drying ink markers, dirt produced from ink markers and not able to write on some projector screen (specially made by doff material). An interactive whiteboard is to elaborate the whiteboard function digitally. Interactive whiteboard is a large, touchCorresponding Author: Budi Yulianto, Bina Nusantara University, Jl. K.H. Syahdan No.9, Jakarta 11480, Indonesia sensitive board which is connected to a digital projector and a computer. The projector displays the image from the computer screen on the board. The computer can be controlled by touching the board, either directly or with a special pen (Higgins and Hall, 2005).

With interactive whiteboard, a lecturer can teach interactively and work with multimedia features, which is a better learning for a later adaptation to the learner's profile (Douidi et al., 2006). Lecturers can write or draw anything on the board digitally and able to capture the writing on the board and then save or share it to students for reviewing. Not only cover the drawbacks on previous whiteboard version, the interactive whiteboard are also expected can increase student interest in teaching learning activities in classroom (Yulianto et al., 2013).

State of the art of this research is to design an interactive whiteboard application with applying multimedia concept to support effective learning environment in classroom. Interactive whiteboard can also increase the interaction between teachers and students as well as students' motivation and enjoyment from teachers' viewpoints (Lan and Hsiao, 2011). The interactive 
whiteboard system can be made by arranging few basic devices. The devices are WiiMote and InfraRed LED Marker. WiiMote (also known as Nintendo Wii Remote) is a wireless game console device from Nintendo Wii (Dewi, 2011). In general, the player holds the WiiMote and pointed it on TV or monitor that has a sensor bar. The sensor bar consists of 2 groups of infrared LED. WiiMote can detect the coordinate position ( $\mathrm{x}$ and $\mathrm{y}$ ), rotational motion and distance between WiiMote and infrared LED (Leal et al., 2011). Wiimote as an input device is to estimate the movements. With those functions, WiiMote can control the cursor on Nintendo Wii game machine (Lee, 2008). By using capabilities of Wiimote, it offers a low cost interactive and viable electronic whiteboard. It also looks at the possibility of whether this much cheaper technology can be fully utilized to create better tools for in-class learning (Singh et al., 2010).

\subsection{Proposed System}

With Nintendo Wii concept, interactive whiteboard can be made with an InfraRed LED Marker, a WiiMote device, a projector and a computer based application. Lecturer will use the InfraRed LED Marker to replace the ink markers. A WiiMote is placed right above the projector. It will capture the InfraRed LED Marker movement as the lecturer write on the projector screen. InfraRed LED Marker movement will be sent from WiiMote to computer via Bluetooth connection (Fig. 2). The basic idea of WiiMoteis to record the motion of the user's movements and translate them into acceleration data to be used by WiiMote console for in-game movements (Rooney et al., 2011).

The application will provide all features that lecturers usually use and few additional features that can make teaching learning activities more attractive. Teachers can write using Free Draw tool. This tool replaced the traditional ink marker functions. Teachers can change the marker's color easily using Change Tool Color. Teachers can also clear the whiteboard using Erase tool on application. This tool replaced the traditional whiteboard's eraser. When teachers want to mark important thing on the whiteboard, teacher can use the Highlight tool. The Draw Shape tool provides the teachers ability to draw shape, such as line, rectangle and circle. Teachers can also record his/her teaching session using Audio Video Recording feature or capture the whiteboard clearly using Snapshot feature so that all the students can review the teaching material at home. All the whiteboard snapshot can be combined into one softcopy file using the Merge Snapshot feature. Undo and redo feature are also available on this application.
Whiteboard areas that can be written are called Canvas. Teacher can change the Canvas setting, color, or number. Classroom administrator can calibrate the devices to work properly and configure it. Tools and features of the application are described as Use Case Diagram shown on Fig. 3 (Whitten and Bentley, 2007).

For teacher comforts in using this application, the user interface was made as simple as possible. The tools are arranged in one toolbox. Each icon describes the tools' functions clearly (Fig. 4). Back-end system will be used for classroom administrator to calibrate the screen (Fig. 5).

\subsection{System Specification}

To implement the system, minimum computer hardware specifications below are required:

- Processor: Intel® Pentium® Dual CPU @ $1.3 \mathrm{GHz}$

- Memory: $512 \mathrm{MB}$

- Available hard disk space: $320 \mathrm{MB}$ (100 MB for application installations, $20 \mathrm{MB}$ for approximately 100 snapshot images, $200 \mathrm{MB}$ for audio video recording result with $240 \mathrm{p}$ quality for $100 \mathrm{~min}$ )

- Bluetooth: Dongle/Built-in

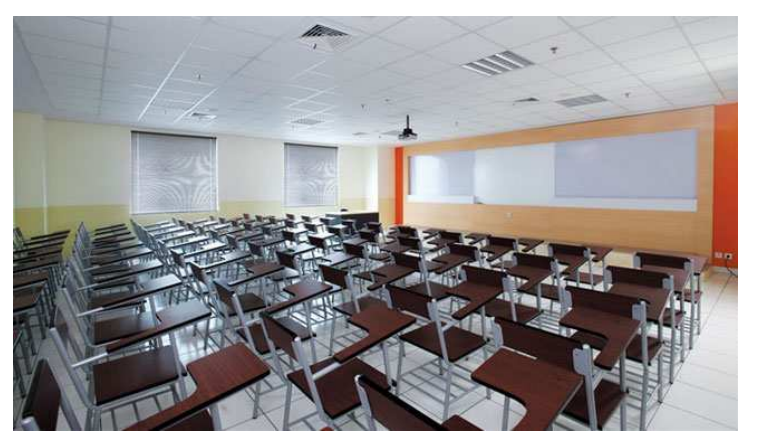

Fig. 1. Classroom with whiteboard and projector

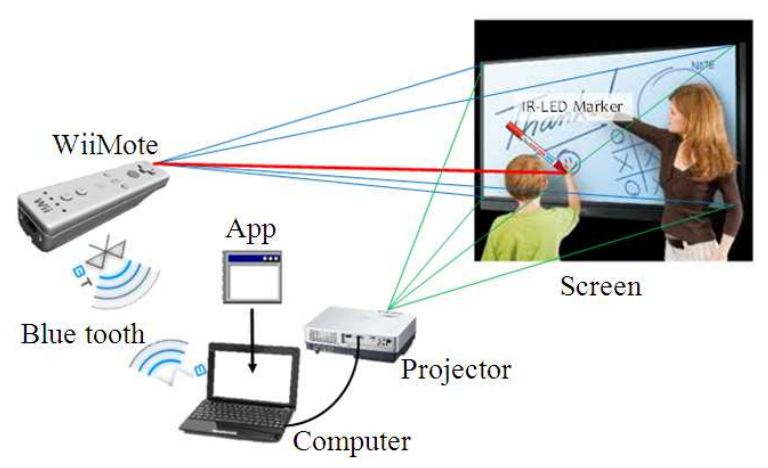

Fig. 2. Bee board system design 


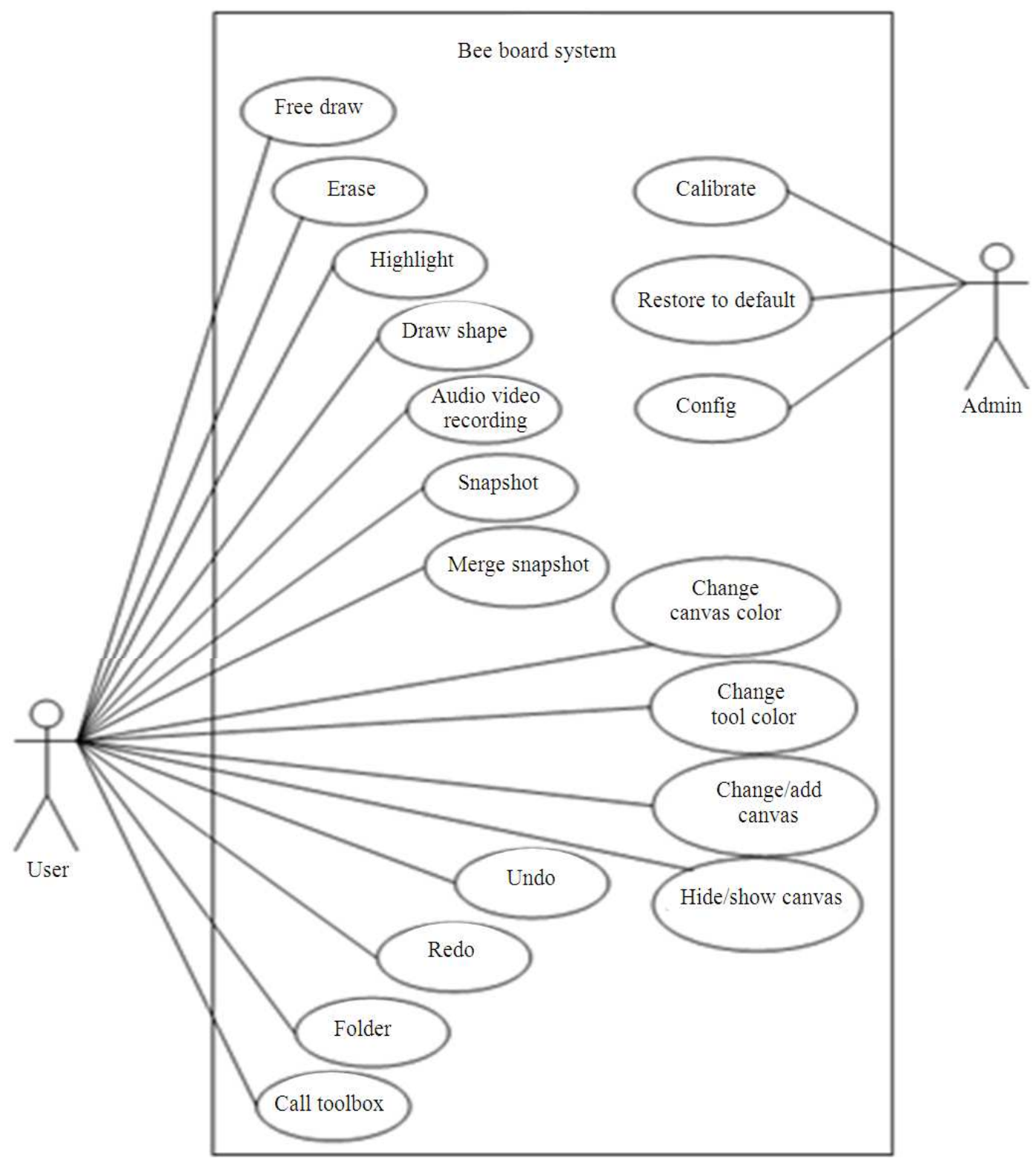

Fig. 3. Use case diagram of bee board system

Minimum software requirement for system implementations are Microsoft Windows XP/Windows 7/Windows 8 operating systems.

Besides computer, hardware below must be available in classroom:

- Projector that is connected to the computer

- WiiMote (Fig. 6) that is connected to the computer via Bluetooth
- InfraRed LED Marker as input device (Fig. 7)

XML is used to store all the Bee Board application's configurations. All attributes for Bee Board application's configurations are described in the tree diagram (Fig. 8).

Unified Modeling Language (UML) are also used in the system design. It was used for visualize and documenting all objects in the system (Booch et al., 2005). The class diagram documentation is shown on Fig. 9. 
Budi Yulianto and Lusiana Citra Dewi / Journal of Computer Science 10 (10): 2117.2123, 2014

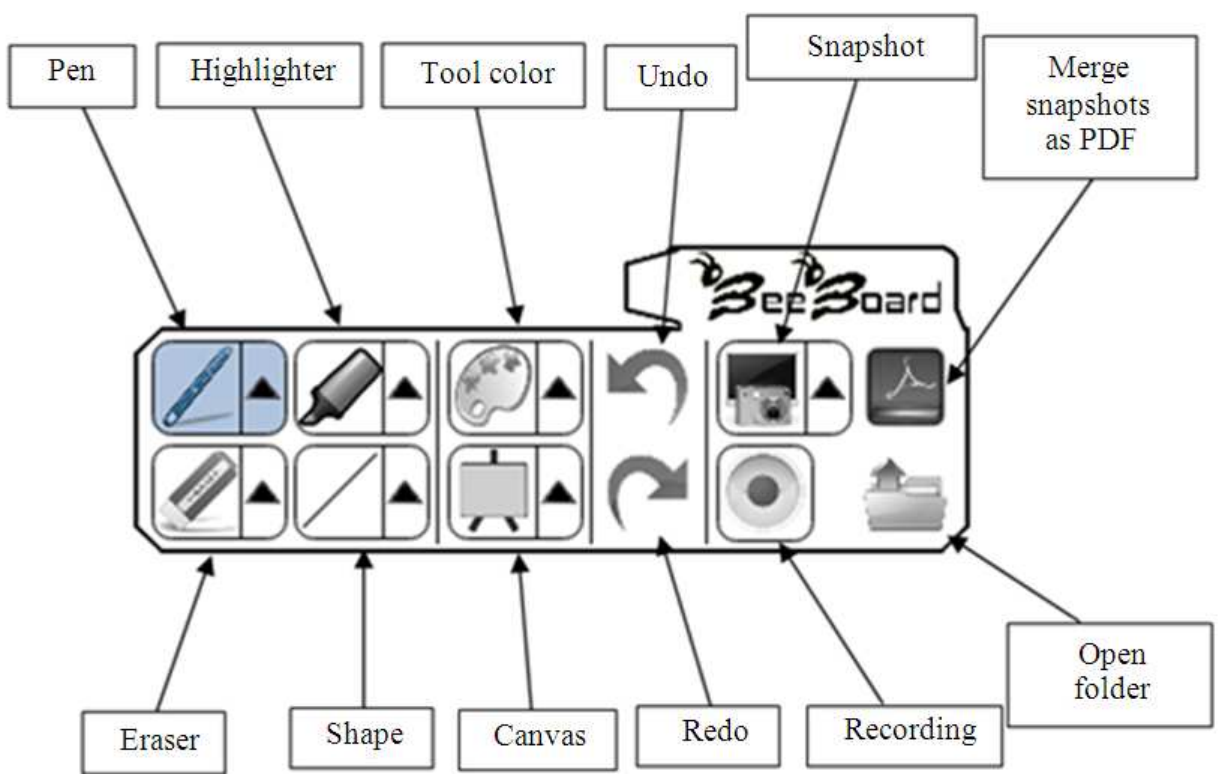

Fig. 4. Bee board toolbox

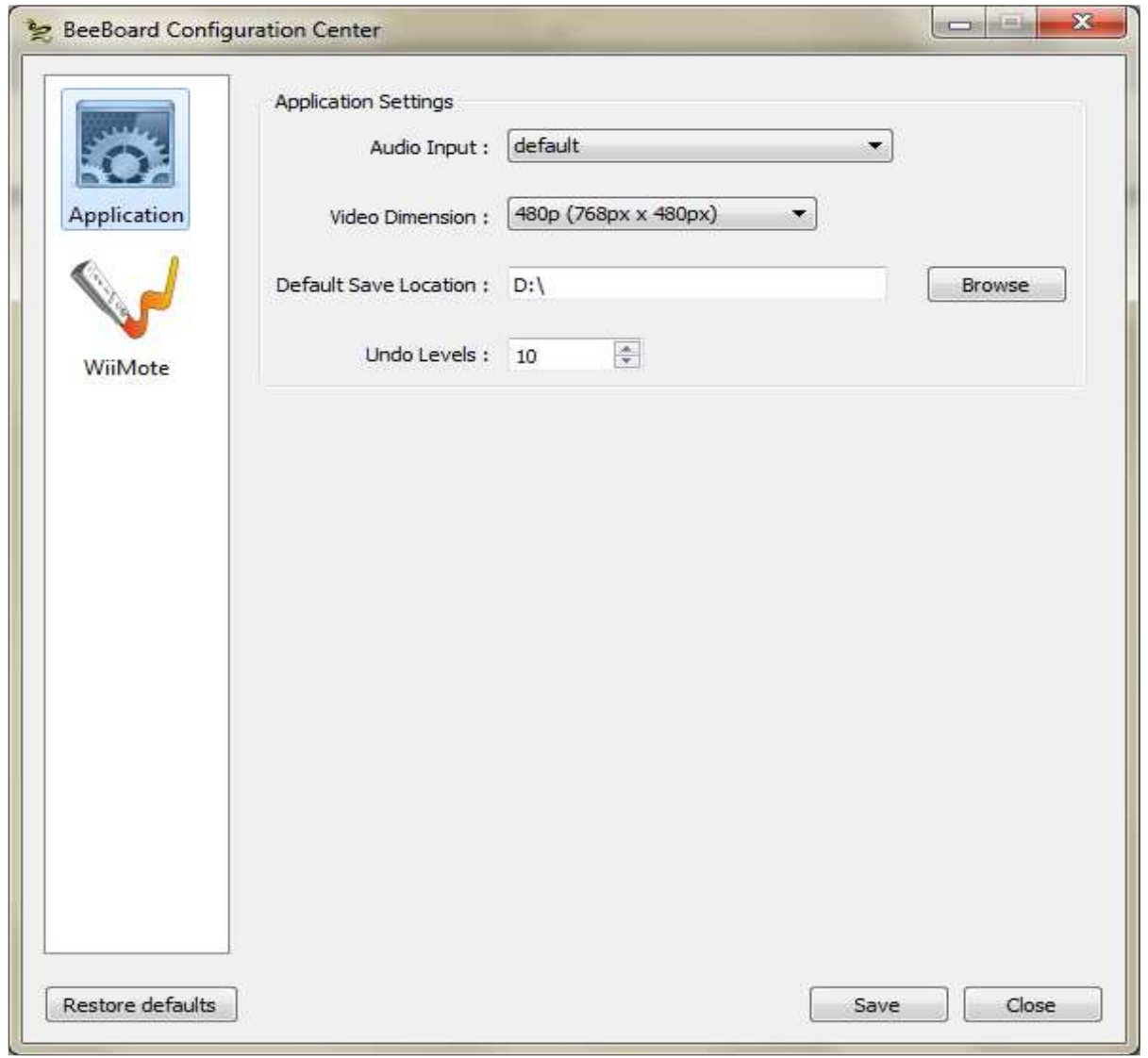

Fig. 5. Back-end system 


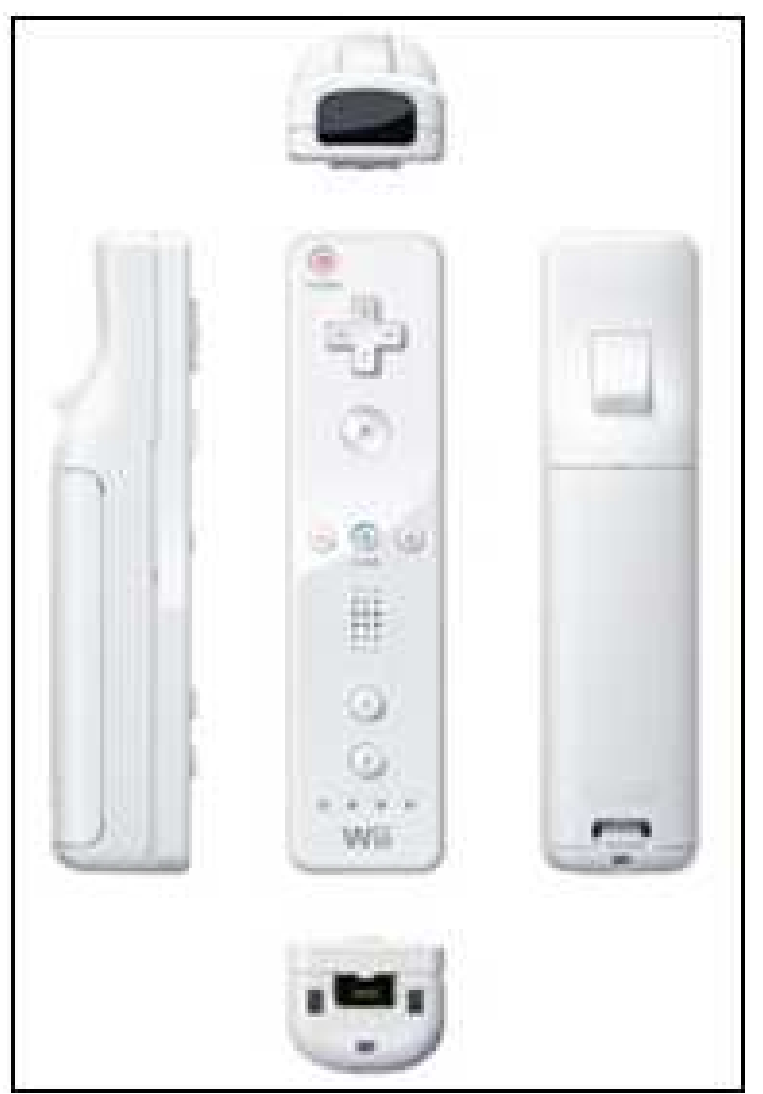

Fig. 6. WiiMote

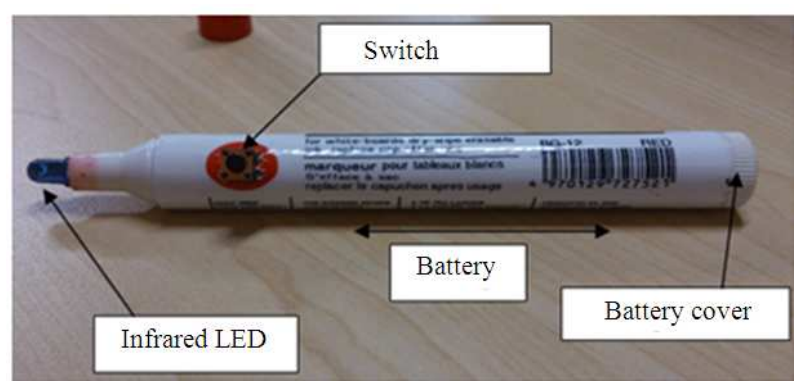

Fig. 7. InfraRedLED marker

\subsection{Experimental Results}

Experiments of the application are done by testing the battery endurance of WiiMote and InfraRed LED Marker and coverage area of WiiMote censor. Experiments are also done for functional activity of Bee Board application.
Table 1. WiiMote battery endurance

\begin{tabular}{ll}
\hline Hour(s) & Battery capacity (\%) \\
\hline 1 & 93 \\
3 & 82 \\
5 & 77 \\
7 & 73 \\
9 & 62 \\
12 & 57 \\
\hline
\end{tabular}

WiiMote use 2 AA size batteries. Experiments result shown that WiiMote could last up to $12 \mathrm{~h}$ (with remain battery capacity 57\%) shown on Table 1.

Below is LED specification that used for InfraRed LED Marker device:

- IR Emitter: 940 NM

- Wavelength: $940 \mathrm{~nm}$

- Voltage: $1.35 \mathrm{~V}$

- Power: $210 \mathrm{mWh}$

- Lifetime: $10000 \mathrm{~h}$

The electricity consumption for InfraRed LED Marker in mAh (milliamp-hour) can be calculated using that specification and the equation below:

$$
\mathrm{Q}(\mathrm{mAh})=\mathrm{E}(\mathrm{Wh}) \times 1000 / \mathrm{V}(\mathrm{v})
$$

Note: $\mathrm{Q}$ is load current in $\mathrm{mAh}, \mathrm{E}$ is power in $\mathrm{Wh}$ (watt-hour) and $\mathrm{V}$ is voltage in volts.

Below is the calculation for single InfraRed LED Marker power consumption per hour:

$$
\mathrm{Q}=0.21 \mathrm{Wh} \times 1000 / 1.35 \mathrm{~V}=155.55 \mathrm{mAh}
$$

The InfraRed LED Marker uses 1 AA size battery. Below is the calculation for InfraRed LED Marker battery durability.

$$
\begin{aligned}
& \text { Durability= capacity } / \text { load current per hour } \\
& =2000 \mathrm{mAh} / 155.55 \mathrm{mAh} \\
& =12.85 \mathrm{~h} \\
& =12 \mathrm{~h} 51 \mathrm{~min}
\end{aligned}
$$

Note: Battery capacity are $2000 \mathrm{mAh}$.

Based on the calculations, the InfraRed LED Marker could last up to $12 \mathrm{~h}$ and 51 min continuously. 
Budi Yulianto and Lusiana Citra Dewi / Journal of Computer Science 10 (10): 2117.2123, 2014

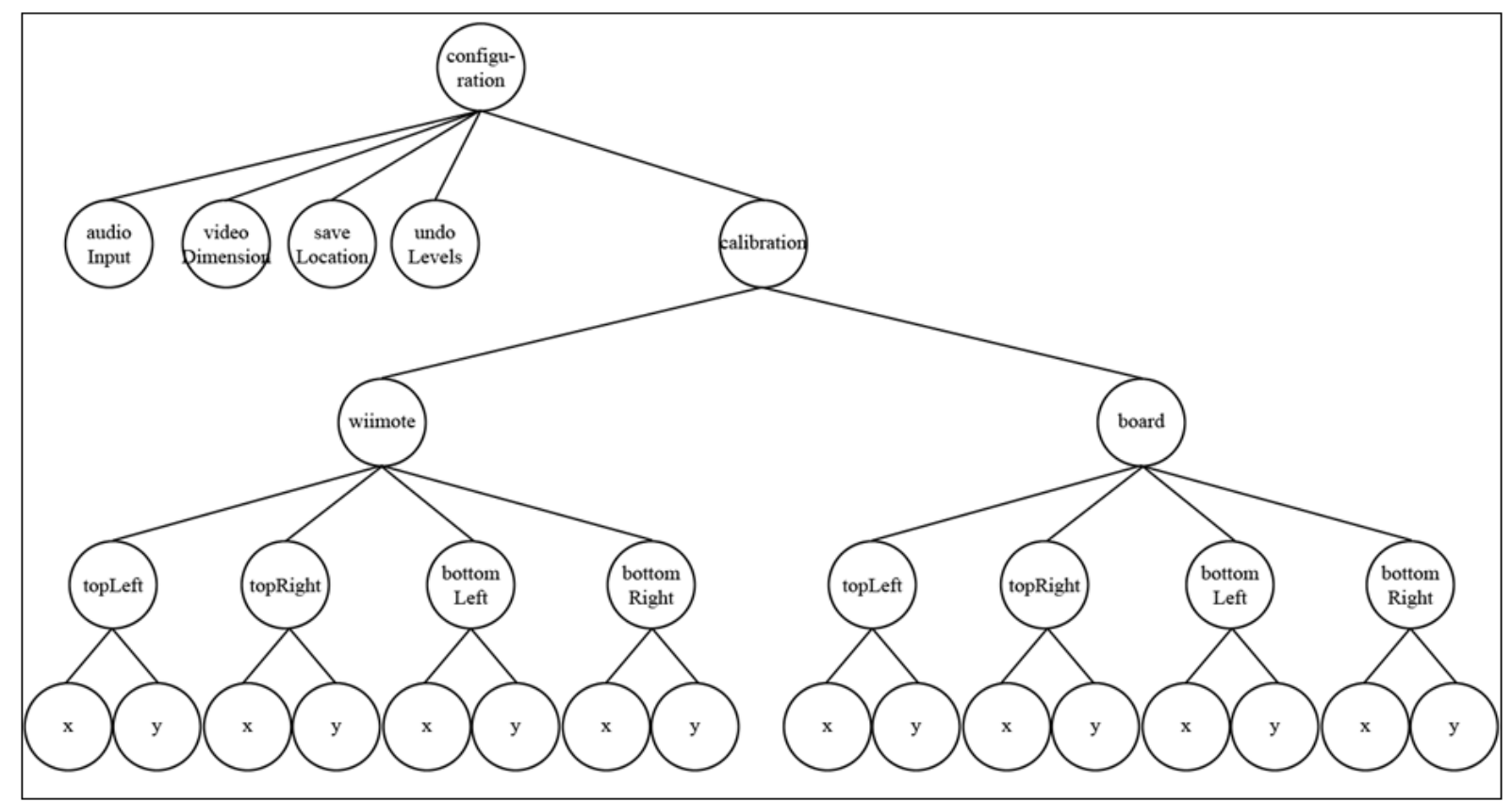

Fig. 8. XML design

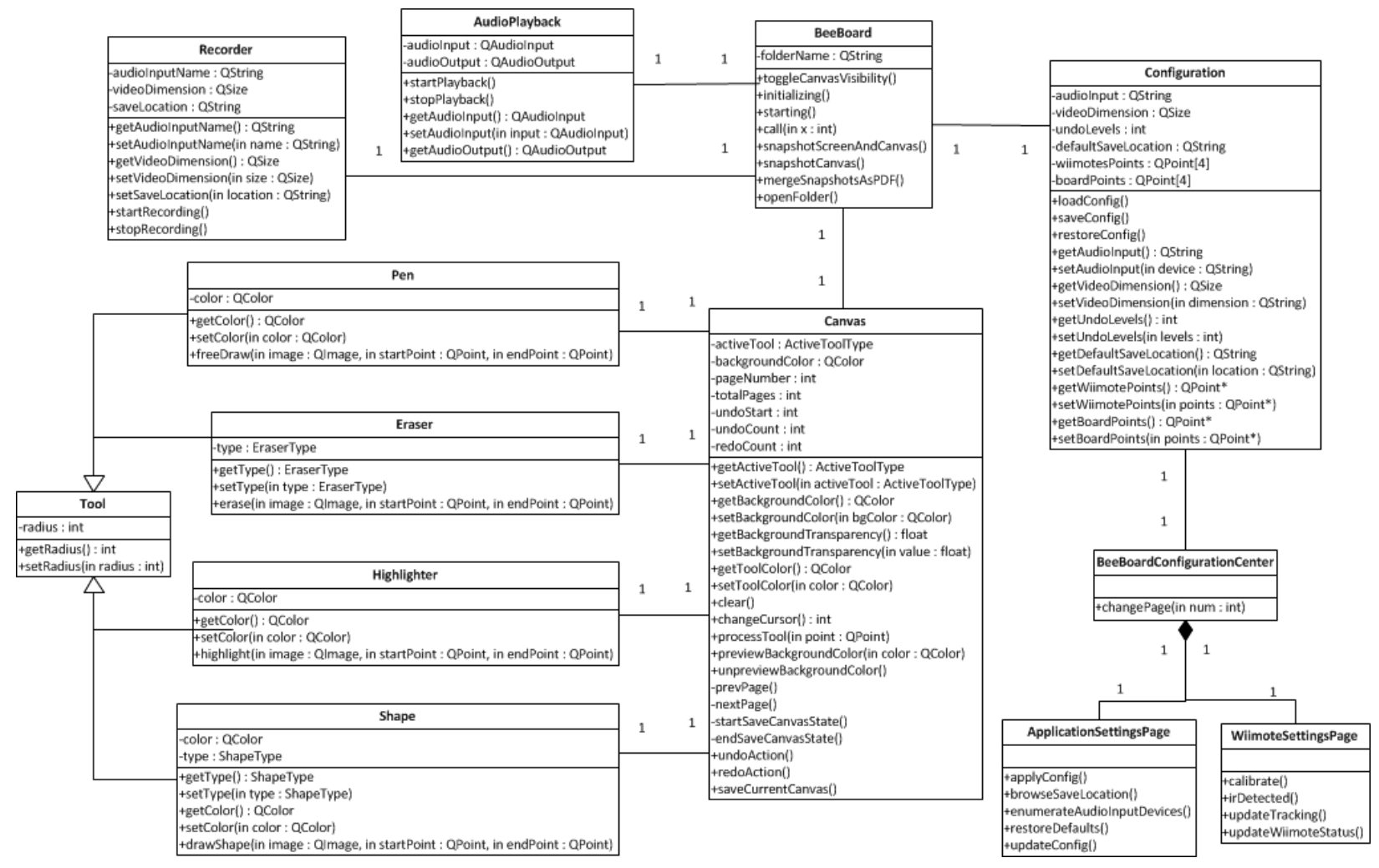

Fig. 9. Class diagram of bee board system 


\section{CONCLUSION}

The system already tested in classroom in Bina Nusantara University, Jakarta. At the first version, the main functionality is only focusing on writing (drawing), erasing, capturing and recording tools. All these functionalities can run well, but for the next version needs several improvement. Features that can be added to the next version are duplication of screen, PowerPoint navigator, mouse click behavior and collaoration systems.

This system can be a cheaper alternative for interactive teaching and learning process. Most users agree that this system can replace the function of inkmarker and recommend that this system is to be used or implemented. Image capturing and video recording can help students to review teaching materials at home or after-class session.

\section{ACKNOWLEDGMENT}

This research was funded by grant from Bina Nusantara University, Jakarta for the year 2013.

\section{REFERENCES}

Booch, G., J. Rumbaugh and I. Jacobson, 2005. The Unified Modeling Language User Guide. 1st Edn., Pearson Education India, New Delhi, ISBN-10: 8131715825. pp: 496

Dewi, L.C., 2011. Wireless technology development: History, now and then. ComTech, 2: 1224-1240.

Douidi, L., M. Djoudi and C. Khentout, 2006. AVUNET Author: An Authoring System for Distance Learning Platform. J. Comput. Sci., 2: 249-256. DOI: 10.3844/jcssp.2006.249.256

Eskicioglu, A.M. and D. Kopec, 2003. The ideal multimedia-enabled classroom: Perspectives from psychology, education and information science. J. Educ. Multimedia Hypermedia, 12: 199-221.
Higgins, S. and I. Hall, 2005. Primary school students' perceptions of interactive whiteboards. J. Comput. Assisted Learn., 21: 102-117. DOI: DOI: 10.1111/j.1365-2729.2005.00118.x

Lan, T.S. and T.Y. Hsiao, 2011. A study of elementary school students' viewpoints on interactive whiteboard. Am. J. Applied Sci., 8: 172-176. DOI: 10.3844/ajassp.2011.172.176

Leal, A.L., J.Á. Fernandez-Rodrigues and J.M. Montero, 2011. Development of a wiimote-based gesture recognizer in a microprocessor laboratory course. Int. J. Emerg. Technol. Learn., 6: 26-30.

Lee, J.C., 2008. Hacking the nintendo wii remote. IEEE Pervasive Comput., 7: 39-45. DOI: 10.1109/MPRV.2008.53

Rooney, F.G., W.J. Soomers and O. Romulo, 2011. Using the wiimote in introductory physics experiments. Phys. Teacher, 49: 16-18. DOI: $10.1119 / 1.3527747$

Singh, D., R. Omar and A. Anuar, 2010. Low cost interactive electronic whiteboard using Nintendo Wii remote. Am. J. Applied Sci., 7: 1458-1463. DOI: 10.3844/ajassp.2010.1458.1463

Yulianto, B., A. Pramita and F.N.M. Fadly, 2011. Aplikasi E-notetaking berbasiskan multimedia untuk kegiatan pencatatan. J. ComTech.

Yulianto, B., M. Shodiq and L.C. Dewi, 2013. Sound and digital class room: Smart way to have a language laboratory. J. Comput. Sci., 9: 708-715. DOI: $10.3844 /$ jcssp. 2013.708 .715

Whitten, J.L. and L.D. Bentley, 2007. Systems Analysis and Design Methods. 6th Edn., McGraw-Hill Companies, Boston, Mass, ISBN-10: 0071215212. pp: 780. 